\title{
Concentration of PDGF-AB, BB and TGF- $\beta 1$ as Valuable Human Serum Parameters in Adipose-derived Stem Cell Proliferation
}

\author{
Fonny Josh ${ }^{1,2}$, Morikuni Tobita ${ }^{1}$, Rica Tanaka ${ }^{1}$, Hakan Orbay ${ }^{3}$, \\ Kasumi Ogata ${ }^{4}$, Koji Suzuki ${ }^{4}$, Hiko Hyakusoku ${ }^{2}$ and Hiroshi Mizuno ${ }^{1}$ \\ ${ }^{1}$ Department of Plastic and Reconstructive Surgery, Juntendo University School of Medicine \\ ${ }^{2}$ Department of Surgery, Hasanuddin University, Indonesia \\ ${ }^{3}$ Department of Plastic and Reconstructive Surgery, Nippon Medical School \\ ${ }^{4} \mathrm{R} \& D$ Central Research Laboratory, JMS Co. Ltd, Hiroshima
}

\begin{abstract}
Introduction: Human serum (HS) has attributes similar to fetal bovine serum (FBS) in the proliferation and differentiation of human adipose-derived stem cells (hASCs) when compared in vitro. The purpose of this study was to determine what types of HS, with respect to the concentrations of endogenous growth factors, could be made available for hASC proliferation.

Methods: HS was collected from 2 groups of healthy donor (freshly isolated HS [n=9], and HS preserved for 4 years [n=7]). All sera were isolated with a Cellaid ${ }^{\circledR}$ HS isolation device (JMS Co., Ltd, Hiroshima, Japan) and then classified into 3 groups based on the concentrations (high, middle, and low) of platelet-derived growth factor (PDGF)-AB, PDGF-BB, and transforming growth factor-beta 1 (TGF- $\beta 1$ ) by means of enzyme-linked immunoassay screening. The hASCs were isolated from subcutaneous fat using a collagenase enzymatic digestion process and were cultured in control media, each supplemented with HS from a different group. Cell numbers were counted on days $2,4,7$, and 14, and the relationship between cell proliferation and the level of each growth factor was investigated.

Results: The proliferation of hASCs correlated with the concentration of each growth factor. The cut-off points for PDGF-AB, PDGF-BB, and TGF- $\beta 1$ in HS [necessary for hASC proliferation when compared with FBS] were $10 \mathrm{ng} / \mathrm{mL}, 1.5 \mathrm{ng} / \mathrm{mL}$, and $15 \mathrm{ng} / \mathrm{mL}$, respectively. There was no correlation between the storage period of HS and the proliferation potential of hASCs.

Conclusions: These results suggest that the effectiveness of HS on hASC proliferation depends on the concentrations of endogenous PDGFs. In addition, the Cellaid ${ }^{\circledR}$ device used in this study allows the simultaneous release of several growth factors from platelets, and our results have shown that it can be used to collect HS for future hASC-based therapies.

(J Nippon Med Sch 2013; 80: 140-147)
\end{abstract}

Key words: adipose-derived stem cells, human serum, platelet-derived growth factor $A B$, platelet-derived growth factor $\mathrm{BB}$, transforming growth factor $\beta 1$

Correspondence to Hiroshi Mizuno, MD, PhD, Department of Plastic and Reconstructive Surgery, Juntendo University School of Medicine, 2-1-1 Hongo, Bunkyo-ku, Tokyo 113-8421, Japan

E-mail: hmizuno@juntendo.ac.jp

Journal Website (http://www.nms.ac.jp/jnms/) 


\section{Introduction}

Concerns have been raised about the potential of cell-based therapies used in clinical trials for a wide range of disease ${ }^{1-4}$. At present, the quantity and accessibility of human adipose tissue means that adipose-derived stem cells (ASCs) are promising candidates for use in regenerative medicine ${ }^{5,6}$. The rapid increase in the number of clinical trials and the many publications related to human ASCs (hASCs) gives new hope to both patients and physicians. However, the clinical use of hASCs raises several issues, including the use of fetal bovine serum (FBS) for expanding the cells in vitro, because FBS contains xenogeneic antigens, which are associated with a risk of zoonotic transmission ${ }^{7.8}$. These issues have led many researchers to focus on finding the most suitable, safe, and economical serum alternatives that have FBS-like properties but are not of animal origin'.

Human serum (HS) is the primary option for an alternative to FBS because it is abundantly available, safe for autologous use, and can be donated by the subject at the same time as fat tissue collection ${ }^{10}$. Studies comparing hASCs cultured in medium supplemented with HS and in medium supplemented with FBS have demonstrated a range of results giving rise to the optimum percentage of $\mathrm{HS}$ required to produce comparable levels of cell proliferation $^{11,12}$. Additionally, the data suggest that factors present within HS affect its activity. We already know that HS is enriched with growth factors and complement and that their concentrations vary among subjects ${ }^{13.14}$. Therefore, in the present study, we sought to determine to what extent endogenous growth factors in HS as culture medium supplements influence hASC proliferation.

\section{Materials and Methods}

\section{Culture of ASCs}

The ethics committee of Juntendo University School of Medicine, Tokyo, Japan, approved all procedures in the present study (Number 2012050).

Adipose tissue was obtained with written informed consent from 3 patients undergoing elective surgery, and the hASCs obtained were processed according to our established protocol. Briefly, adipose tissue was washed vigorously with phosphate-buffered saline (PBS; Gibco-BRL, Grand Island, NY, USA) then minced into small pieces using scissors. After digestion with $0.15 \%$ collagenase (Wako Pure Chemical Industries, Ltd., Osaka, Japan) at $37^{\circ} \mathrm{C}$ for 30 minutes, an equal volume of control medium (Dulbecco's Modified Eagle's Medium [DMEM; Gibco-BRL]) supplemented with 10\% FBS (Gibco-BRL) and 1\% antibiotic/ antimycotic (Gibco-BRL)] was added to neutralize the collagenase activity. Next, the cell suspension was centrifuged at 1,500 rpm for 5 minutes, the cell pellet was resuspended in control medium, and the cells were plated onto cell culture dishes (Becton, Dickinson and Company, Franklin Lakes, NJ, USA). The dishes were incubated at $37^{\circ} \mathrm{C}$ in a humidified atmosphere containing $5 \% \mathrm{CO}_{2}$, and the medium was changed twice weekly. Passaging was performed when the cells had reached $80 \%$ to $90 \%$ confluence. The ASCs from passage 2 were used for the subsequent cell proliferation analyses.

\section{Preparation of Supplements and Media}

To isolate fresh HS, whole blood was collected from healthy volunteer donors $(n=16$; mean age: 34.8 years; range: 30-43 years) with a closed bag system containing glass beads (Cellaid $^{\circledR}$, JMS Co., Ltd., Hiroshima, Japan) and incubated at room temperature for 30 minutes with gentle agitation. After centrifugation at $2,000 \mathrm{~g}$ at $4^{\circ} \mathrm{C}$ for 10 minutes, the fresh HS was transferred into another tube, heat-inactivated at $56^{\circ} \mathrm{C}$ for 30 minutes, and then stored at $4^{\circ} \mathrm{C}$ until use (Fig. 1).

For cryopreservation, freshly isolated HS was stored for an initial 24 hours at $-20^{\circ} \mathrm{C}$ and then stored at $-80^{\circ} \mathrm{C}$. Rapid thawing was carried out at $37^{\circ} \mathrm{C}$ before use. For the present experiment, freshly isolated HS (obtained from 9 donors) and HS stored for 4 years (obtained from 7 donors) were compared.

\section{Measurement of Growth Factors with Enzyme- linked Immunosorbent Assay}

Commercially available enzyme-linked 

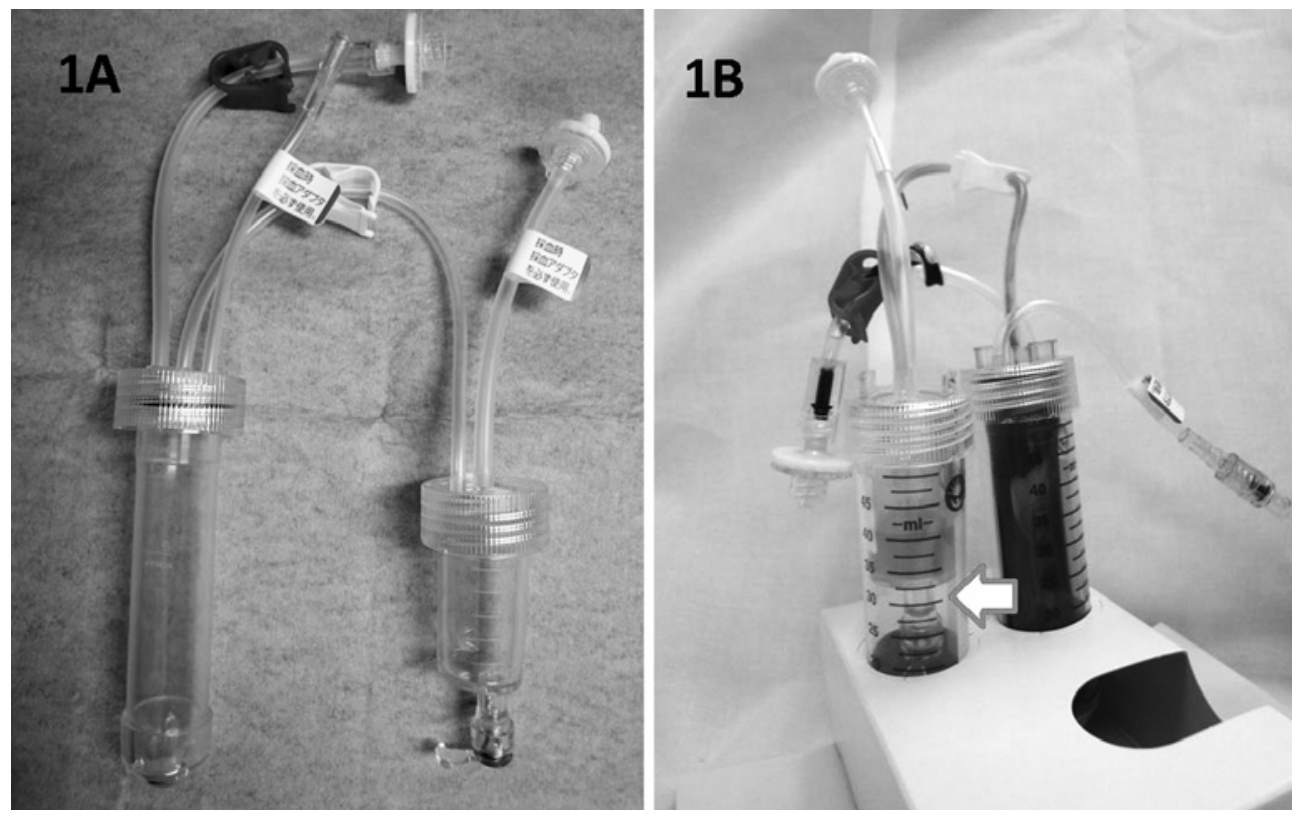

Fig. 1 Cellaid ${ }^{\circledR}$ human serum collection kit (1A). Pure HS after transfer to another tube (1B). All procedures were performed with the closed bag system. (Arrow: part of collected serum)

Table 1 Levels of growth factors based on PDGF-AB, PDGF-BB, and TGF- $\beta 1$ concentrations within HS

\begin{tabular}{lcccccc}
\hline $\begin{array}{c}\text { Growth } \\
\text { factors }\end{array}$ & \multicolumn{2}{c}{$\begin{array}{c}\text { High } \\
(\mathrm{ng} / \mathrm{mL})\end{array}$} & \multicolumn{2}{c}{$\begin{array}{c}\text { Middle } \\
(\mathrm{ng} / \mathrm{mL})\end{array}$} & \multicolumn{2}{c}{$\begin{array}{c}\text { Low } \\
(\mathrm{ng} / \mathrm{mL})\end{array}$} \\
\hline PDGF-AB & $>15$ & $\mathrm{n}=7$ & $10-15$ & $\mathrm{n}=6$ & $<10$ & $\mathrm{n}=3$ \\
PDGF-BB & $>2.5$ & $\mathrm{n}=6$ & $1.5-2.5$ & $\mathrm{n}=6$ & $<1.5$ & $\mathrm{n}=4$ \\
TGF- $\beta 1$ & $>25$ & $\mathrm{n}=4$ & $15-25$ & $\mathrm{n}=8$ & $<15$ & $\mathrm{n}=4$ \\
\hline
\end{tabular}

immunosorbent assay (ELISA) kits (Quantikine ${ }^{\circledR}$, R\&D Systems, Minneapolis, MN, USA) were used according to the manufacturer's instructions to measure concentrations of the growth factors platelet-derived growth factor (PDGF) - AB (\#DHD00B), PDGF-BB (\#DBB00), and transforming growth factor (TGF)- $\beta 1$ (\#DB100). Samples of fresh and stored HS were divided into 3 groups (high, middle, and low) according to the concentrations of each growth factor, as follows: PDGF-AB, $>15 \mathrm{ng} /$ $\mathrm{mL}$ (high), $10-15 \mathrm{ng} / \mathrm{mL}$ (middle) and $<10 \mathrm{ng} / \mathrm{mL}$ (low); PDGF-BB, $>2.5 \mathrm{ng} / \mathrm{mL}$ (high), $1.5-2.5 \mathrm{ng} / \mathrm{mL}$ (middle) and $<1.5 \mathrm{ng} / \mathrm{mL}$ (low); and TGF- $\beta 1,>25 \mathrm{ng} /$ $\mathrm{mL}$ (high), $15-25 \mathrm{ng} / \mathrm{mL}$ (middle) and $<15 \mathrm{ng} / \mathrm{mL}$ (low) (Table 1).

\section{Cell Proliferation}

Passage 2 hASCs were seeded on to 24 -well plates
(Becton, Dickinson and Company) at a density of 4,500 cells $/ \mathrm{cm}^{2}$. The cells were cultured in DMEM with $10 \%$ HS from each of the 3 groups containing different concentrations of growth factors. The hASCs were also incubated in DMEM with 10\% FBS as controls. Three different lots of FBS were used as references to eliminate differences caused by lot-tolot variability. Cells were trypsinized and counted with a hemocytometer on days $2,4,7$, and 14 .

\section{Statistical Analysis}

The statistical analyses were performed with the software program GraphPad Prism version 5.04 (GraphPad Software, Inc., La Jolla, CA, USA) and SAS version 9.02 (SAS Institute Inc., Cary, NC, USA). All values are stated as the mean \pm standard deviation. The results were analyzed with the paired t-test, one-way analysis of variance, and Tukey's 


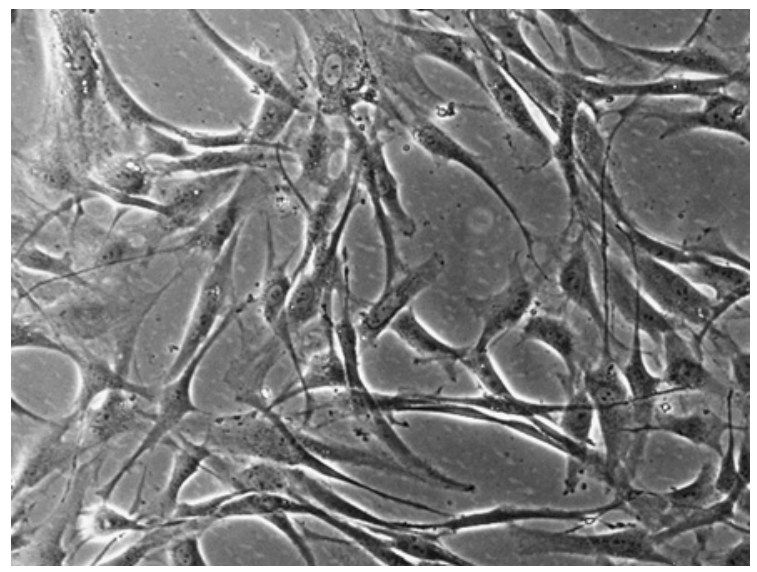

Fig. 2 Primary hASC culture grown in FBSsupplemented medium. These cells exhibited a fibroblast-like morphology.

multiple comparison test. Differences were considered significant at $\mathrm{p}<0.05$.

\section{Results}

Isolated ASCs Were Proliferated Successfully in FBS-supplemented Medium

After enzymatic digestion of the adipose tissue, the stromal vascular fraction containing hASCs was isolated and easily expanded in the control medium. These cells exhibited fibroblast-like morphology and reached $80 \%$ confluence at 6 to 7 days of culture (Fig. 2). When hASC cells at passage 2 were incubated in adipogenic, osteogenic, and chondrogenic media ${ }^{5,6}$, they were successfully induced to differentiate towards the adipogenic, osteogenic, and chondrogenic lineages, as evidenced by positive staining with Oil red O, von Kossa, and Alcian Blue, respectively (data not shown).

\section{Measurement of Growth Factors}

The measured levels of PDGF-AB, PDGF-BB, and TGF- $\beta 1$ in fresh and stored HS were $18.49 \pm 5.475$ $\mathrm{ng} / \mathrm{mL}$ and $11.05 .1 \pm 5.815 \mathrm{ng} / \mathrm{mL} ; 2.558 \pm 0.951 \mathrm{ng} /$ $\mathrm{mL}$ and $1.363 \pm 0.9371 \mathrm{ng} / \mathrm{mL}$; and $21.68 \pm 8.623 \mathrm{ng} /$ $\mathrm{mL}$ and $19.90 \pm 7.243 \mathrm{ng} / \mathrm{mL}$, respectively. Statistically significant differences were observed between the concentrations of PDGF-AB and PDFG$\mathrm{BB}$ in fresh and stored HS $(\mathrm{p}<0.05)$, but no significant difference was found for TGF- $\beta 1$ (Fig. 3).

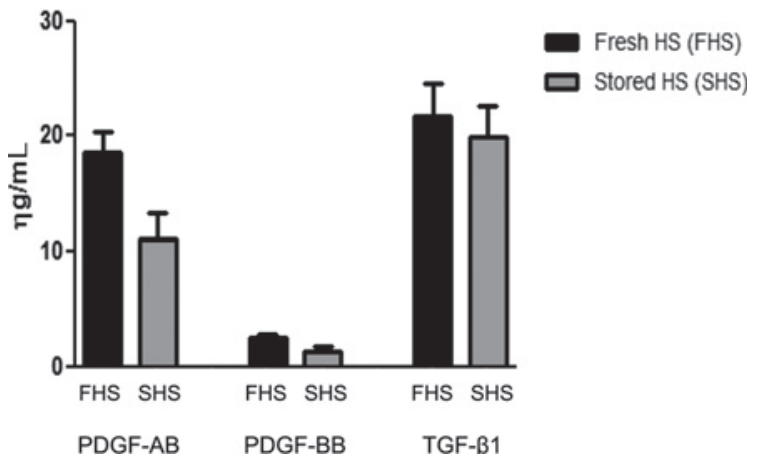

Fig. 3 Differences in the content of each growth factor between fresh HS and stored HS. Statistically significant differences were found between fresh HS and HS preserved for 4 years with respect to the PDGF-AB and PDGF-BB concentrations, but no difference was found for TGF- $\beta 1$.

\section{Effects of PDGF-AB on hASC Proliferation Capacity}

High PDGF-AB-containing HS consistently yielded the highest cell counts at each time point. A significant effect on cell proliferation due to PDGF$\mathrm{AB}$ levels was indicated by the difference between the HS with high and low levels on day 2 (high $[24,486 \pm 10,465$ cells $]$ vs. middle $[1,7042 \pm 3,709$ cells $]$ vs. low $[3,563 \pm 1,313$ cells $]$ vs. FBS $[18,237 \pm 9,358$ cells]; $\mathrm{p}<0.05$ ). On day 4, hASCs cultured in HS with high PDGF-AB levels demonstrated a significant difference in cell numbers compared with those cultured in low-PDGF-AB HS or FBS. Furthermore, the middle PDGF-AB concentration HS also showed a significant difference from the low-concentration HS (high [121,487 $\pm 33,098$ cells] vs. middle [98,417 \pm $21,184$ cells $]$ vs. low $[17,708 \pm 5,242$ cells $]$ vs. FBS $[66,717 \pm 22,742$ cells]; $\mathrm{p}<0.05)$. However, no significant difference in cell number was observed on day 7 among all PDGF-AB levels and FBS (high $[412,945 \pm 135,230$ cells $]$ vs. middle $[362,327 \pm 258,588$ cells] vs. low $[71,875 \pm 71,195$ cells] vs. FBS [147,938 \pm 48,214 cells]; p>0.05). Finally, on day 14, a significant difference was observed in hASC cell proliferation between the high and middle PDGF-AB HS compared with low-concentration HS (high $[615,848 \pm 159,465$ cells $]$ vs. middle [513,542 $\pm 183,549$ cells] vs. low $[95,833 \pm 147,119$ cells] vs. FBS [423,438 $\pm 115,467$ cells]; $p<0.01$ ) (Fig. 4a). 
F. Josh, et al
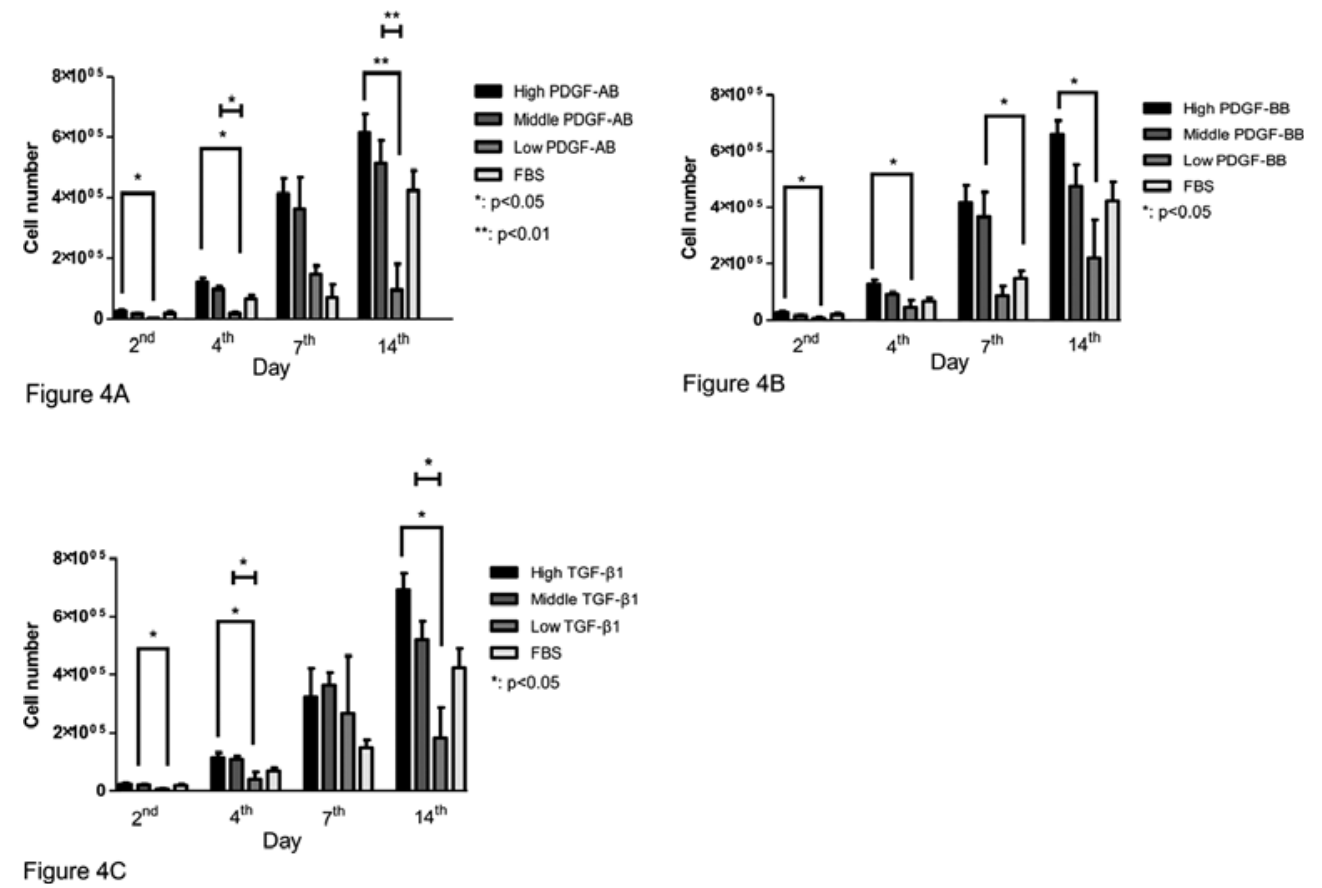

Fig. 4 Effects of each growth factor in HS on hASC proliferation. (a) Effects of PDGF-AB on hASC proliferation. HS containing a high PDGF-AB concentration had a positive effect on hASC proliferation. (b) Effects of PDGF-BB on hASC proliferation. Similar results to PDGF-AB were observed for PDGF-BB. (c) Effects of TGF- $\beta 1$ on ASC proliferation. Similar results to PDGF-AB were observed for TGF- $\beta 1$.

\section{Effects of PDGF-BB on ASC Proliferation}

\section{Capacity}

Statistical differences were observed only between HS with high and low PDGF-BB concentrations for each of the time points: day 2 (high [26,130 $\pm 11,429$ cells] vs. middle $[16,042 \pm 3,340$ cells $]$ vs. low $[7,828 \pm$ 8,598 cells] vs. FBS $[18,237 \pm 9,358$ cells]; $\mathrm{p}<0.05$, day 4 (high $[127,235 \pm 35,442$ cells $]$ vs. middle [92,084 \pm 16,892 cells] vs. low $[44,531 \pm 5,242]$ vs. FBS $[66,717 \pm$ 6,065]; p<0.05), day 7 (high [417,082 \pm 147,651] vs. middle $[366,013 \pm 213,157$ cells $]$ vs. low $[71,875 \pm$ 71,195 cells] vs. FBS [147,938 \pm 48,215 cells]; $\mathrm{p}<0.05$ ), and day 14 (high [65,8782 $\pm 121,433$ cells] vs. middle $[491,071 \pm 188,729$ cells $]$ vs. low $[95,833 \pm 147,119$ cells] vs. FBS [423,438 \pm 115,467 cells]; p<0.05) (Fig. 4 b).

\section{Effects of TGF- $\beta 1$ on ASC Proliferation}

\section{Capacity}

On day 2, a statistically significant difference in cell number was found between the HS with middle and low TGF- $\beta 1$ levels (high [22,828 $\pm 10,565$ cells] vs. middle $[20,760 \pm 9,241$ cells $]$ vs. low $[5,835 \pm 4,740$ cells] vs. FBS $[18,237 \pm 9,358$ cells]; $\mathrm{p}<0.05)$. On day 4 , significant differences were demonstrated for HS with high and middle TGF- $\beta 1$ levels compared with HS with low TGF- $\beta 1$ levels (high $[126,833 \pm 27,296$ cells] vs. middle $[10,8785 \pm 34,693$ cells $]$ vs. low [40,656 $\pm 46,095$ cells] vs. FBS [66,717 $\pm 22,742$ cells]; $\mathrm{p}<0.05$ ). On day 7 , no significant differences were observed for hASC proliferation between HS with different levels of TGF- $\beta 1$ and FBS (high [323,211 \pm 195,121 cells] vs. middle $[364,677 \pm 119,263$ cells] vs. low $[267,485 \pm 395,514$ cells] vs. FBS [147,938 \pm 48,215 cells]; p>0.05). Finally, on day 14, cells grown in HS containing the middle TGF- $\beta 1$ concentration demonstrated a significant difference compared with the low-concentration HS (high [69,3750 \pm 108,756 cells $]$ vs. middle $[521,430 \pm 178,380$ cells $]$ vs. low $[182,813 \pm 211,412$ cells $]$ vs. FBS $[423,438 \pm 115,467$ cells]; p <0.05) (Fig. 4c).

\section{Discussion}

Cell-based therapies, such as those using hASCs, are becoming the new treatments of choice for 
many diseases and injuries. The properties of subcutaneous fat tissue, such as the abundance and ease of harvest with less donor site morbidity, have allowed the use of hASCs to advance to the stage of clinical trials ${ }^{15}$. In particular, hASCs have promising prospects for use in regenerative medicine and have been shown to be clinically useful in such procedures as breast reconstruction and $\operatorname{augmentation}^{16,17}$, wound healing ${ }^{18,19}$, and bone/skeletal tissue repair ${ }^{20,21}$.

Although hASCs hold great promise for future cell-based therapies, current investigations are focused on establishing a culture method using an appropriate serum with varied supplements ${ }^{11,12}$. Although FBS is the most widely used medium supplement in hASC culture, stem cells cultured with FBS express the xenoantigen $\mathrm{N}$ glycolylneuraminic acid (Neu 5 Gc $)^{7}$. The administration of cells contaminated by xenoantigens may cause immunologic rejection of the injected cells and may also lead to more serious complications $^{22}$. As an alternative supplement to FBS, HS is now being considered for in vitro cell culture.

HS contains many proteins, including growth factors, immunoglobulins, and complement, and produces various comprehensive effects in cell culture which may not be compensated for by the simple administration of recombinant growth factors ${ }^{9,1023}$. Although various important growth factors, such as fibroblast growth factor, vascular endothelial growth factor, epidermal growth factor, hepatocyte growth factor, PDGF, the TGF- $\beta$ family, and the Wnt family, have effects on cell proliferation and differentiation ${ }^{24}$, in particular, serum PDGF and TGF- $\beta 1$ are key factors in the expansion and differentiation of mesenchymal stem cells (MSCs) ${ }^{25}$. PDGFs are potent mitogens of $\mathrm{ASCs}^{26}$. PDGF consists of homodimers or heterodimers of $\mathrm{A}$ - and $\mathrm{B}$ polypeptide chains, which exert their biological effects by binding to 2 structurally related tyrosine kinase receptors, PDGF-a receptor and PDGF-b receptor $^{24,27}$. Upon binding to the ligand, the PDGF receptors homodimerize or heterodimerize and then phosphorylate each other on specific tyrosine residues; they subsequently activate diverse signaling cascades, including SHP-2, Src, PLC-g, Ras, protein kinase A, phosphatidylinositol 3-kinase, and the mitogen-activated protein kinases. Activation of these signaling pathways contributes to the PDGFinduced physiological responses, such as proliferation, actin cytoskeleton rearrangements, and chemotaxis $^{28}$. In addition, TGF- $\beta$ affects cells from the chondrogenic lineage in vivo, promoting initial stages of mesenchymal condensation, prechondrocyte proliferation, production of extracellular matrix, and cartilage-specific molecule deposition while inhibiting terminal differentiation ${ }^{24,29}$. As the predominant isoform of TGF- $\beta$, TGF- $\beta 1$ plays an important role in promoting chondrogenic differentiation in chondroblasts and in mesenchymal cells $^{30}$. TGF- $\beta 1$ induces the proliferation of human MSCs $^{31,32}$. TGF- $\beta 1$ also induces Smad3-dependent nuclear accumulation of $\beta$-catenin in MSCs, which is required for the stimulation of MSC proliferation. However, there are no parameters for HS proteins have been established. Additionally, the percentage of HS used in hASC culture has not been standardized, although some studies of hASCs cultured with 2 different percentages of HS, 10\% and $15 \%$, have shown similar results to FBS with respect to cell growth and differentiation ${ }^{11,12}$.

Therefore, the purpose of the present study was to investigate whether the cultivation of hASCs is affected by the serum concentrations of the HS growth factors PDGF-AB, PDGF-BB, and TGF- $\beta 1$. Furthermore, cell proliferation was compared between fresh HS and HS preserved with deepfreezing. The results of the comparative analysis of PDGF-AB, PDGF-BB, and TGF- $\beta 1$ concentrations showed that all 3 growth factors had similar effects on hASC proliferation. Significant differences were evident only between the different concentrations of each growth factor. HS with high concentrations of PDGF-AB (>15 ng/mL), PDGF-BB (>2.5 ng/mL), and TGF- $\beta 1 \quad(>25 \mathrm{ng} / \mathrm{mL})$ exhibited greater cell proliferation than did HS with middle growth factor concentrations or FBS, indicating that such high concentrations are the most effective for cell proliferation. HS with low levels of the 3 growth factors showed lower cell growth than did HS with higher levels of growth factors. One or all of these 
growth factors could be used as screening parameters for choosing the optimal HS for hASC culture. Furthermore, our data showed that the effectiveness of HS on hASC proliferation does not depend on the preservation period but instead depends on the concentrations of these endogenous growth factors.

Cellaid $^{\circledR}$, which is a special closed bag system for collecting HS and PDGFs simultaneously within 1 hour without the addition of heparin or thrombin, was used in the present study. Human platelets possess alpha granules that contain cytokines and growth factors, which are released through degranulation of the alpha granules following the addition of thrombin and calcium chloride or by lysis during freeze-thaw cycles $^{33,34}$; however, the addition of thrombin may be a concern in clinical applications because it induces proteolysis in serum ${ }^{35}$. Furthermore, the concentrations of PDGFs (PDGF$\mathrm{AB}, \mathrm{PDGF}-\mathrm{BB}$, and TGF- $\beta 1$, in particular) within $\mathrm{HS}$ are related to the efficiency of their release from platelet granules following freeze-thaw cycles, which have not been standardized ${ }^{25}$. Use of the Cellaid $^{\circledR}$ closed bag system reduces any risk of viral or bacterial infections and foreign proteins and does not require the use of thrombin or freeze-thaw cycles ${ }^{36}$.

In conclusion, HS could provide an alternative to FBS for use in hASC proliferation when used with a closed serum collection system such as Cellaid ${ }^{\circledR}$. With this technique, HS containing concentrated growth factors, such as PDGF-AB, PDGF-BB, and TGF- $\beta 1$, could be made readily available for cell culture for use in future cell-based therapies. Further studies involving larger numbers of donors will be necessary to confirm the effects of PDGF-AB, PDGF-BB, and TGF- $\beta 1$ concentrations in HS on hASC proliferation and differentiation.

\section{References}

1. Mizuno H, Tobita M, Uysal AC: Concise review: Adipose-derived stem cells as a novel tool for future regenerative medicine. Stem Cells 2012; 30: 804-810.

2. Ankrum J, Karp JM: Mesenchymal stem cell therapy: Two steps forward, one step back. Trends Mol Med 2010; 16: 203-209.

3. Sanz-Ruiz R, Gutiérrez Ibañes E, Arranz AV, Fernández Santos ME, Fernández PL, Fernández-
Avilés F: Phases I-III Clinical Trials Using Adult Stem Cells. Stem Cells Int 2010; 2010: 579142.

4. Trounson A, Thakar RG, Lomax G, Gibbons D: Clinical trials for stem cell therapies. BMC Med 2011; 9: 52.

5. Zuk PA, Zhu M, Mizuno H, et al.: Multilineage cells from human adipose tissue: implications for cellbased therapies. Tissue Eng 2001; 7: 211-228.

6. Zuk PA, Zhu M, Ashjian P, et al.: Human Adipose Tissue Is a Source of Multipotent Stem Cells. Mol Biol Cell 2002; 13: 4279-4295.

7. Komoda H, Okura H, Lee CM, et al:: Reduction of Nglycolylneuraminic acid xenoantigen on human adipose tissue-derived stromal cells/mesenchymal stem cells leads to safer and more useful cell sources for various stem cell therapies. Tissue Eng Part A 2010; 16: 1143-1155.

8. Heiskanen A, Satomaa T, Titinen S, et al.: Nglycolylneuraminic acid xenoantigen contamination of human embryonic and mesenchymal stem cells is substantially reversible. Stem cells 2007; 25: 197-202.

9. Kobayashi $\mathrm{T}$, Watanabe $\mathrm{H}$, Yanagawa $\mathrm{T}$, et al.: Motility and growth of human bone-marrow mesenchymal stem cells during ex vivo expansion in autologous serum. J Bone Joint Surg Am 2005; 87: 1426-1433.

10. Blande I, Bassaneze V, Lavini-Ramos C, et al.: Adipose tissue mesenchymal stem cell expansion in animal serum-free medium supplemented with autologous human platelet lysate. Transfusion 2009; 49: 2680-2685.

11. Lindroos B, Aho KL, Kuokkanen H, et al.: Differential Gene Expression in Adipose Stem Cells Cultured in Allogeneic Human Serum Versus Fetal Bovine Serum. Tissue Eng Part A 2010; 16: 2281-2294.

12. Bieback K, Ha VA, Hecker A, et al: Altered Gene Expression in Human Adipose Stem Cells Cultured with Fetal Bovine Serum Compared to Human Supplements. Tissue Eng Part A 2010; 16: 3467-3484.

13. Jenhani F, Durand V, Ben Azouna N, et al.: Human cytokine expression profile in various conditioned media for in vitro expansion bone marrow and umbilical cord blood immunophenotyped mesenchymal stem cells. Transplant Proc 2011; 43: 639-643.

14. Mimura S, Kimura N, Hirata M, et al.: Growth factordefined culture medium for human mesenchymal stem cells. Int J Dev Biol 2011; 55: 181-187.

15. Gimble JM, Bunnell BA, Guilak F: Human adiposederived cells: an update on the transition to clinical translation. Regen Med 2012; 7: 225-235.

16. Yoshimura K, Sato K, Aoi N, Kurita M, Hirohi T, Harii K: Cell-assisted lipotransfer for cosmetic breast augmentation: supportive use of adipose-derived stem/stromal cells. Aesthetic Plast Surg 2008; 32: 4855.

17. Moseley TA, Zhu M, Hedrick MH: Adipose-derived stem and progenitor cells as fillers in plastic and reconstructive surgery. Plast Reconstr Surg 2006; 118: $121 \mathrm{~S}-128 \mathrm{~S}$.

18. García-Olmo D, García-Arranz M, Herreros D, Pascual I, Peiro C, Rodríguez-Montes JA: A phase I clinical trial of the treatment of Crohn's fistula by adipose mesenchymal stem cell transplantation. Dis Colon Rectum 2005; 48: 1416-1423. 
19. Akita S, Akino K, Hirano A, Ohtsuru A, Yamashita S: Mesenchymal stem cell therapy for cutaneous radiation syndrome. Health Phys 2010; 98: 858-862.

20. Lendeckel S, Jödicke A, Christophis $P$, et al: Autologous stem cells (adipose) and fibrin glue used to treat widespread traumatic calvarial defects: case report. J Craniomaxillofac Surg 2004; 32: 370-373.

21. Mesimäki K, Lindroos B, Törnwall J, et al.: Novel maxillary reconstruction with ectopic bone formation by GMP adipose stem cells. Int J Oral Maxillofac Surg 2009; 38: 201-209.

22. Tekkatte C, Gunasingh GP, Cherian KM, Sankaranarayanan K: "Humanized" stem cell culture techniques: the animal serum controversy. Stem Cells Int 2011; 2011: 504723.

23. Adkins JN, Varnum SM, Auberry KJ, et al:: Toward a Human Blood Serum Proteome: Analysis By Multidimensional Separation Coupled With Mass Spectrometry. Mol Cell Proteomics 2002; 1: 947-955.

24. Rodrigues M, Griffith LG, Wells A: Growth factor regulation of proliferation and survival of multipotential stromal cells. Stem Cell Res Ther 2010; 1: 32 .

25. Doucet C, Ernou I, Zhang Y, et al.: Platelet lysates promote mesenchymal stem cell expansion: a safety substitute for animal serum in cell-based therapy applications. J Cell Physiol 2005; 205: 228-236.

26. Kang YJ, Jeon ES, Song HY, et al:: Role of c-Jun Nterminal kinase in the PDGF-induced proliferation and migration of human adipose tissue-derived mesenchymal stem cells. J Cell Biochem 2005; 95: 1135-1145.

27. Heldin $\mathrm{CH}$, Ostman A, Ronnstrand L: Signal transduction via platelet-derived growth factor receptors. Biochim Biophys Acta 1998; 1378: F79113.

28. Heldin $\mathrm{CH}$, Westermark B: Mechanism of action and in vivo role of platelet-derived growth factor. Physiol Rev 1999; 79: 1283-1316.

29. van der Kraan PM, Blaney Davidson EN, Blom A, van den Berg WB: TGF-beta signaling in chondrocyte terminal differentiation and osteoarthritis: modulation and integration of signaling pathways through receptor-Smads. Osteoarthritis Cartilage 2009; 17: 1539-1545.

30. Han Y, Wei Y, Wang S, Song Y: Enhanced chondrogenesis of adipose-derived stem cells by the controlled release of transforming growth factorbetal from hybrid microspheres. Gerontology 2009; 55: 592-599.

31. Jian H, Shen X, Liu I, Semenov M, He X, Wang XF: Smad3-dependent nuclear translocation of betacatenin is required for TGF-betal-induced proliferation of bone marrow-derived adult human mesenchymal stem cells. Genes Dev 2006; 20: 666674 .

32. Watabe T, Miyazono K: Roles of TGF-beta family signaling in stem cell renewal and differentiation. Cell Res 2009; 19: 103-115.

33. Harlan JM, Thompson PJ, Ross RR, Bowen-Pope DF: Alpha-thrombin induces release of platelet-derived growth factor-like molecule(s) by cultured human endothelial cells. J Cell Biol 1986; 103: 1129-1133.

34. Textor JA, Tablin F: Activation of Equine PlateletRich Plasma: Comparison of Methods and Characterization of Equine Autologous Thrombin. Vet Surg 2012. doi: 10.1111/j.1532-950X.2012.01016.x.

35. O'Mullan P, Craft D, Yi J, Gelfand CA: Thrombin induces broad spectrum proteolysis in human serum samples. Clin Chem Lab Med 2009; 47: 685-693.

36. Mizuno N, Shiba H, Ozeki Y, et al.: Human autologous serum obtained using a completely closed bag system as a substitute for foetal calf serum in human mesenchymal stem cell cultures. Cell Biol Int 2006; 30: 521-524.

(Received, October 10, 2012)

(Accepted, November 15, 2012) 